\title{
Are Companies Aiming to be More Regional or More Global?
}

\author{
Wendy S.C. Hii \\ University of Sunderland \\ Victor Shan Ko \\ Presentation College
}

In the context of globalization of the world economy, this paper is to evaluate the argument that international business has become more regional than global and to discuss some of the major implications for production strategies of companies. The authors point out that there are indications showing companies lean toward regionalization more than globalization. This observation should help newly developed companies to identify what trends of business structure matrix have been popular among well-established Fortune 500 corporations in the industry. Furthermore, by understanding that regionalization is more imperative than globalization, a new firm can plan its production and sales force in an appropriate direction.

\section{INTRODUCTION}

For a firm to even, think about having a "global strategy," it must first have a sustainable regional strategy typically. A global strategy would mean extraordinary of investment into logistics, staff development, and infrastructure expansion to handle the additional volume of business and a solid arsenal of business tools for such cross-border competition.

There are numerous examples of Fortune 500 corporations that execute well globally applied a regional-oriented growth policy before adopting a global one. For example, McKesson, (medical distributor), Tesco (supermarket), Walgreen's (pharmacy chain), Tesla Motors (electric vehicle maker) and Buffalo Wild Wings (sports bar restaurant), just to name a few. These companies all have one similar characteristics and that is they started as a regional powerhouse of what they do (Dewhurst \& Heywood, 2012). In fact, successful global companies have been focusing on a regional level more so than they do globally. A deeper look into why they are so large today shown that they all have a strong regional level business strategy.

Sally Smith, long-time president and CEO of Buffalo Wild Wings franchise, tells employees that global advantage only matters when regional and local levels are flourishing (Appendix: Table 1). Buffalo Wild Wings is a relatively new franchise to titans such as Pizza Hut and KFC. In 1996, Sally was the chief financial officer for this franchise of chicken wings. The entire chain was still comparatively young, with about seventy outlets altogether (Dewhurst \& Heywood, 2012). Today it has about fifty international branches and most of those are in Canada (14) and Mexico (14). These two countries also act as the median centers for regional branches for Americas - hence the regional strategies still apply. 
In terms of regionalized thinking, Toyota may have gone furthest in developing the knowledge base in this area. As CEO Fujio Cho says, "Toyota anticipates continuing globalization with enhancement by localization and therefore we can attain independence for our vehicle operations in each region." This characteristic is the common point among today's most robust corporations that experience sustainable growth (Ghemawat, 2005). The entrepreneurs of these proven organizations have shared two common truths about this globalized world.

First, geographic and other peculiarities have not been undermined by the rise of internationalism. Realistically, quite contrary, these regional peculiarities are becoming more and more important for the firm to secure several long-term customer bases (Bolton, 2012). Second, regional-focused measures are not merely a bridge between local (country-focused) and international policies but a concrete set of strategies that applied in combination with local and global initiatives. Together, these regionally focused strategies can significantly boost an organization's financial performance.

\section{MORE ABOUT REGIONAL-FOCUS}

One notable trend we saw is the emergence of regional commerce blocs, i.e., ten Southeast Asian countries such as the Association of Southeast Asian Nations (Figure 1). The purpose of the bloc is to facilitate additional cross-border economic integration among regional/adjacent countries. The process of globalization would expand this concept by promoting more free trades and lowing tariffs among member nations (VanderPal \& Ko, 2014). Statistically speaking, there is an upsurge of imports and exports in the latter half of the twentieth century. This phenomenon is primarily motivated by economic activities within regions than across regions.

Conversely, a closer glance at the country-level figures indicates that rising cross-border economic cooperation has been complemented by heightening levels of regionalization. That is, regional-focused strategies are the enabler of cross-border integration that eventually leads to greater globalization (Charron, 2016). As Figure 2 and 3 show, the upsurge of imports and exports in the last two decades of the twentieth century is propelled more by economic activities within regions than across regions. These statistics also discredit the widely held idea by diehard global strategists that trade activities are stimulated more by international trades. The actual result shows that regional intragroup commerce is higher relative to commerce outside of regional scope (international).

In addition, country-specific data likewise pinpoint that foreign direct investment (FDI) is more regional than global (Capello \& Dentinho, 2013). Statistical data from a trade and development conference by the United Nations depicts that for the G20 countries that make up for nearly eighty-five percent of the world's trades, the median share of intra-regional foreign direct investment was greater than fifty percent in 2012.

The degree and tenacity of regionalization in business activities echo the ongoing significance not only of geographic closeness but also of sociocultural, organizational, and, partially, governmental effectiveness. The following factors are interrelated (Ghemawat, 2005): 1) Cities that are close to one another share commonalities besides other peculiarities. 2) These resemblances have fortified in the past few decades through varies free trade deals, regional trade agreements and tax treatments, and even currency alliance such as the European Union and the North American Free Trade Agreement (NAFTA) among Canada, Mexico, and the United States.

Paradoxically, dissimilarities among countries within a geographical region may blend with the similarities to magnify the region's total financial growth (Ghemawat, 2005). For example, North American companies in various industries set up operations near-shoring production facilities to Canada or Mexico, thus leveraging competitive advantages across socioeconomic differences between the two countries while keeping the niche of geographic closeness and sociocultural and governmental similarities, which further distant countries, such as Brazil, do not savor.

In addition, data from various multinational corporations' (MNCs) international sales suggests regionalization is the way to ensure a sure footing in a large geographical area and these individual regional centers further enhance sales globally (Rugman \& Verbeke, 2004). Susan Feinberg at Rutgers 
Business School has completed a study among American multinational firms operating in only one foreign country; there is a sixty percent probability that the country is Canada - a regionalization mindset among those corporate decision-makers. Even the largest MNCs exhibit a noteworthy regional preference instead of merely globalize effort to expand operations.

A study conducted by Rugman and Verbeke (2004, January) shows that around eighty percent of Fortune-500 largest MNCs generate at least fifty percent of their revenue from their home regions. Only two percent (nine firms in this study) derive twenty percent or more of their revenue from other regions of the globe. These large organizations can source raw materials, information technology, science, and other forms of investments from around the globe. However, economic activities are likely to concentrate in particular hubs, cities or regions in a few regions of the globe (Moore \& Rugman, 2002). Prime examples of these industrial clusters include the new 5G mobile communication technology in Dallas/Houston, Texas; designer fashion and fabric manufacturing in the area encompassing Madrid, Spain; and the science and technology hub called Silicon Fen around Cambridge, UK.

During the last decade, large sectors have undergone an increase in industry concentration as measured by the Herfindahl Index (a classic measure of industry concentration). As the index goes higher, it points to a larger market share of the largest firms. Data have shown that the Herfindahl Index in North America has doubled in the last decade after being stagnant for the previous two decades (Verbeke \& Asmussen, 2016). There were similar patterns appear in other sectors of economies such as mobile computing, beverages, consumer food manufacturing, and construction materials. In other words, global oligopoly firms had the incentives to build up powerhouse positions at the local and regional levels.

Researchers found that even more business interactions that are competitive are often regionally focused (Moore \& Rugman, 2002). Take the cases in the U.S., Oklahoma as a hub for natural gas, wind, and petroleum energy; and Wichita, Kansas, nicknamed the "Air Capital of the World" is home to aerospace engineering due to the presence of a cluster of aircraft makers such as Raytheon, Cessna, Spirit AeroSystems, Beechcraft, Bombardier Learjet, Boeing, and Airbus' engineering facility. The importance of commerce hubs has given cities and states more influence to compete domestically and globally to entice head offices, new factories, and research \& development laboratories (Ezcurra \& Rodríguez-Pose, 2013).

\section{REGIONAL PRODUCTION STRATEGIES}

Elon Musk, founder and CEO of Tesla Motors, states that regional teams are crucial to his firm's globalization initiatives. Musk's Tesla currently has one factory located in Fremont, California, which was previously operated under Toyota and General Motors. Tesla uses this factory to build its Model S, Model X, and the latest mass production of Model 3 electric vehicles. Tesla Motors has plans to open two more factories in 2019 in order to supply electric vehicles internationally to Canada and Mexico.

A "comparative advantage" good is a product that a country can produce cheaper and better than another country producing it. For example, soybeans are such a comparative advantage commodity for the United States. With adequate annual rainfall and vast fertile land spread across the Midwestern states Kansas, Colorado, Oklahoma, Missouri, South Dakota, Nebraska, and Iowa, those U.S. farmers can produce roughly five billion bushels of soybeans in 2018 which converts to thirty-three million metric tons of soybeans (Statista, 2018) - all of that volume was exported to China.

On the other hand, since China is not the most efficient nor cost-effective producer for this commodity, China became the world's largest buyer of soybeans because it is cheaper to buy from the United States than to grow them in China. Besides production time and cost, comparative advantages in production can be generated by (Cooke et al., 2015), for example, differences in the labor forces' skill sets and differences in the employment of physical capital, and differences in the quality or availability of those required natural resources used as inputs.

Instead of choosing the regions based on geographic location, regions are formed based on countryspecific elements (Cooke et al., 2015), such as the degree of economic openness to trade, the share of 
actual gross domestic product in the form of investments, the method of waste recycling, logistics, the legal system, business culture, and distribution of trade and production.

Pricing may be able to come down depends on how the management decide to position their brands - should the price of their products reflect luxury status (Reynolds, 2016)? Or would lower prices help the firm to conquer a competitive market? American furniture giant Ashley Home Stores, Inc. based out of Wisconsin, is a home furnishings manufacturer and retailer, known in the U.S. for its quality and value, faltered initially in China due to local competitors' labor costs and wood material being much lower (Reynolds, 2016). In order to survive, the company switch production for the Chinese market right there in China. Ashley also started using more materials that are locally-sourced. The result, Ashley Home Stores switched their tactic to aggressively trim their retail prices and offered discount incentives to better reflect its core brand value and jumpstart higher sale volume at the regional level.

Next, we should think about how a manufacturer faces its supply chain complexity and taking risks of having non-performing suppliers. When it comes to outsourcing products and services among regional suppliers, handling supply chains can be a challenging process (Reynolds, 2016). Nevertheless, the complexity of supply chains raises the likelihood of dealing with suppliers who have unethical or even illegal commercial practices. One growing concern is the risk of exposure to fraudulent business deals and financial frauds among in-between agents.

Honda Motor Company's initial investments in Ohio, United States, which was a daring move to establish a manufacturing presence in the firm's most noteworthy sales region, the North American market, is a good example of a successful portfolio strategy. What this approach yield was a surging public relation value Honda was able to create in the heartland of the world's largest automotive market at the time in the early 2000s. Honda also found an identifiable competitive advantage - the Honda Manufacturing System which was formulated in Japan but could be adapted to the new factories in the United States (Nguyen, 2006). Similarly, Maytag/KitchenAid brands are outsourcing most of its small kitchen appliances from India. There is a long list of multinational companies are in the process of widening their core global production operations into China to serve the neighboring countries adjacent to China - Indonesia, Vietnam, Cambodia, Thailand, Malaysia, and Singapore.

Regarding regional business hubs, the creation of a production and procurement team was to provide an increased commitment to transfer the Honda Manufacturing System from Japan to the newer production hubs in America at a time when overseas production was being raised rapidly. But even as its hubs gain momentum, Honda persists to reduce the number of its major production platforms and seek additional specialization through interregional collaborations (Nguyen, 2006). The North American production project for Honda Motors in the early 2000s played a crucial role in making the company one of the most successful automakers globally.

In addition, regional unification does have a bearing on the MNC's internal distribution of resources and its competitive advantages. Precisely, corporate-level investments in regional adaptation regularly call for a relocation of specific production facilities to the most efficient town/hub to take advantage of regional scale economies (Rugman \& Verbeke, 2004).

In reality, there are so few true "global" multinationals and that sort of render the concept of "globalization" meaningless. Data on foreign assets implies that production is more intra-regional than previously thought and these findings also point to a "regional nature" of foreign assets. Hence, we can generalize them to most other Fortune 500 companies (Rugman \& Verbeke, 2004). Rugman's research suggests that future researchers of international business should focus less on the models of "global" strategy but rather on the regional pattern of trades. Another interesting academic research question in international business is: why do multinational corporations succeed as regional powerhouses even without becoming global?

According to Capello and Dentinho (2013), there are two types of foreign direct investment, horizontal and vertical FDI. "Horizontal FDI" is when a company sets up an outlet or a branch in each market in order to attain proximity to consumers, such as what Honda and Nissan Motors did in North America. On the other hand, a "vertical FDI" is when a company trying to pursuit for lower production 
costs instead of by market access. Under vertical FDI, headquarters are usually located in advanced countries with high wages and their plants are located in countries with low wages.

Commonly, a multinational corporation would mix their horizontal and vertical location strategies. Nevertheless, empirical evidence indicates that the strategy of proximity to the market (horizontal strategy) tends to dominate (Capello \& Dentinho, 2013). This is a very important decision for the corporate executives to consider carefully because it involves the trade-off between both economies of scale and concentration of production costs where it is lowest and proximity to the market.

The value-added concept forces us to rethink how we can draw on the advanced production competencies in a region. This makes the firm more flexible and be able to deliver products that are far more stable in quality even for small batches. The production competencies also aid in how the firm builds complementary services around its production activities (Herstad \& Brekke, 2012). However, surely, we need to keep track of what goes on internationally as well in terms of predicting/forecasting competitors' next move. Are our regional machine developers and production tool engineers able to keep up with our demands? What is our customers' feedback regarding our strategy of serving local and regional first? Regional business strategy is a relatively new body of knowledge that represents a continuous stream of critical information for a success-seeking regional manager to tap into and select from.

\section{CONCLUSION}

As we can see from above examples, most global firms are not truly $100 \%$ globalized, but rather a conglomerate makes up of clusters of regional firms with solid regional influence. How would a newly appointed senior manager capitalize this information for expanding the core business to the next level? To start, say, in the Midwestern United States, it is far more cost-effective to reach out to your local and regional states' prospective customers than to serve those customers in California or Alaska. This is known as the geographical limitation for service coverage. To reach your potential customers on a national level, the senior executive would need to expand his sales channel and product delivery logistics nationwide rather than focusing on a few regional states. Second, we should also consider the financial constraint; a national expansion strategy would cost the firm a lot more in terms of sales agents, production staff, unit managers, communication and logistic costs. The cost of marketing alone would mean national radio/television/social media exposure for your products. This business ambition does require a great deal of planning and monitoring of progress.

Next, when the firm is attempting to reach the rest of the nation, its managers would discover that there is diversity among its newly found customers in terms of purchasing behaviors. This diversity would require the firm to have, say, bilingual marketing brochures, bilingual product manuals, revised product appearance, and revised advertising for marketing communications, etc. These actions would be especially important for doing business in the state of New Mexico and the New England states. Certain aspects of a product may no longer appeal to a new group of clients due to the consumers' unique sociocultural differences from those living in the Midwest region.

On the contrary, fine wine from California, seafood from Alaska, and special rare cheeses from the New England states may not sell well in the Midwestern states like Kansas, Missouri, Nebraska, and the Dakotas, etc. This knowledge applies to the product manufacturers, suppliers, distributors, marketers, and in-between-agents as well. Those who understand these sensitive consumer preferences would know how to confidently launch the right product mix to those regional and national markets.

One notable study conducted by Jean-Luc Arregle, a university professor of international business strategy, provide further insights into the "regional approach" after his research on a few hundred multinational firms. Basically, a regional strategy is highly dependent on the concept of "regional institutional complexity." This framework covers cultural diversity as well as institutional diversity that consists of three components found in the PESTEL model. They are the economic environment, legal environment, and the political environment within the region. The successful firms within the research are not homogeneous but also are not tremendously diversified (Arregle, 2016). In fact, these firms all 
benefited greatly from a regional strategy that embraces the "middle-of-the-road" approach or what Arregle calls it, "a happy medium."

In summary, most successful Fortune-500 companies all have one similar characteristic - they started as a regional powerhouse of what they do. As we can see from these examples mentioned, successful "globalized" multinational companies have been focusing on the regional level more so than they do globally. Our in-depth look into the core reason shown that they all have strong regional level business strategies that kept them out of financial woes and led them to a consistent path of growth. The fact that companies do not want to deal with over-the-top diversity, legal requirements and/or sociocultural differences because the core capabilities and skill set of the firm are not interchangeable in other regions. We hope that managers of companies that are newly developed would consider staying the course for the regional growth model and only venture out for the global expansion when the success in regional growth is optimized. After that point, the optima, these managers would start to see diminishing returns in their operations. The awareness in this body of knowledge will determine the operational outcome between a successful expansion and a disastrous mishap.

\section{REFERENCES}

Arregle, J. L., Miller, T., Hitt, M., \& Beamish, P. (2016). How does regional institutional complexity affect MNE internationalization? Journal of International Business Studies, 47(6), 697-722.

Bailey, D., Pitelis, C., \& Tomlinson, P. R. (2018). A place-based developmental regional industrial strategy for sustainable capture of co-created value. Cambridge Journal of Economics, 42(6), $1521-1542$.

Bolton, R. (2012, October). Globalization, Modes of Innovation and Regional Knowledge Diffusion Infrastructures. European Planning Studies, 20(10), 1603-1625.

Capello, R., \& Dentinho, T. P. (2013). Globalization Trends and Regional Development: Dynamics of FDI and Human Capital Flows. JOURNAL OF REGIONAL SCIENCE, 53(4), 732-734.

Charron, N. (2016, July). Diverging cohesion? Globalization, state capacity and regional inequalities within and across European countries. European Urban \& Regional Studies, 23(3), 355-373.

Cooke, D. A., Kose, M. A., Otrok, C., \& Owyang, M. T. (2015, April). Regional vs. Global How Are Countries' Business Cycles Moving Together These Days? The Regional Economist, 4-9.

Dewhurst, M., Harris, J., \& Heywood, S. (2012, June). The global company's challenge. McKinsey Quarterly, June, 1-5.

Ezcurra, R., \& Rodríguez-Pose, A. (2013, December). Does Economic Globalization affect Regional Inequality? A Cross-country Analysis. World Development, 52, 92-103.

Ghemawat, P. (2005). Regional Strategies for Global Leadership. Harvard Business Review, December, $1-23$.

Herstad, S., \& Brekke, T. (2012). Globalization, Modes of Innovation and Regional Knowledge Diffusion Infrastructures. European Planning Studies, 20(10), 1603-1625.

Moore, K., \& Rugman, A. (2002). Don't Think Global - Think Regional. PWC Strategy + Business, $3^{\text {rd }}$ Quarter, 28, 15-20.

Nguyen, D. T. (2006). Building External Manufacturing Capability in Emerging Markets: Honda's Knowledge Transfer and the Role of Local Suppliers' Responsiveness. Journal of Asia-Pacific Business, 7(4), 77-95.

Reynolds, K. (2016). 11 Biggest Challenges of International Business in 2017. Retrieved December 6, 2018, from http://www.hult.edu/blog/international-business-challenges/

Rugman, A., \& Verbeke, A. (2004, January). A Perspective on Regional and Global Strategies of Multinational Enterprises. Journal of International Business Studies, 35(1), 3-18.

Statista. (2018). Production of soybeans in the U.S. from 2000 to 2017 (in 1,000 bushels). Retrieved December 6, 2018, from https://www.statista.com/statistics/192058/production-of-soybeans-forbeans-in-the-us-since-2000/ 
VanderPal, G., \& Ko, V. (2014). An Overview of Global Leadership: Ethics, Values, Cultural Diversity and Conflicts. Journal of Leadership, Accountability \& Ethics, 11(3), 166-175.

Verbeke, A., \& Asmussen, C. G. (2016, October). Global, Local, or Regional? The Locus of MNE Strategies. Journal of Management Studies, 53(6), 1051-1075.

\section{APPENDIX}

TABLE 1

INTERNATIONAL GROWTH FOR BUFFALO WILD WINGS

\begin{tabular}{|c|c|c|c|c|c|}
\hline \multicolumn{6}{|c|}{ International Locations } \\
\hline \multicolumn{6}{|l|}{ Latest Fiscal Year } \\
\hline & 2016 & 2015 & 2014 & 2013 & 2012 \\
\hline Canada & 14 & 14 & 14 & 14 & 7 \\
\hline Mexico & 14 & 10 & 5 & 1 & 0 \\
\hline Panama & 1 & 0 & 0 & 0 & 0 \\
\hline Philippines & 5 & 2 & 0 & 0 & 0 \\
\hline Saudi Arabia & 1 & 1 & 0 & 0 & 0 \\
\hline United Arab Emirates & 1 & 1 & 0 & 0 & 0 \\
\hline Total International Restaurants & $\mathrm{N} / \mathrm{A}$ & N/A & $\$ 19$ & $N / A$ & N/A \\
\hline
\end{tabular}

Source: Buffalo Wild Wings annual financial report (2017)

FIGURE 1

\section{REGIONAL TRADE ASSOCIATIONS}

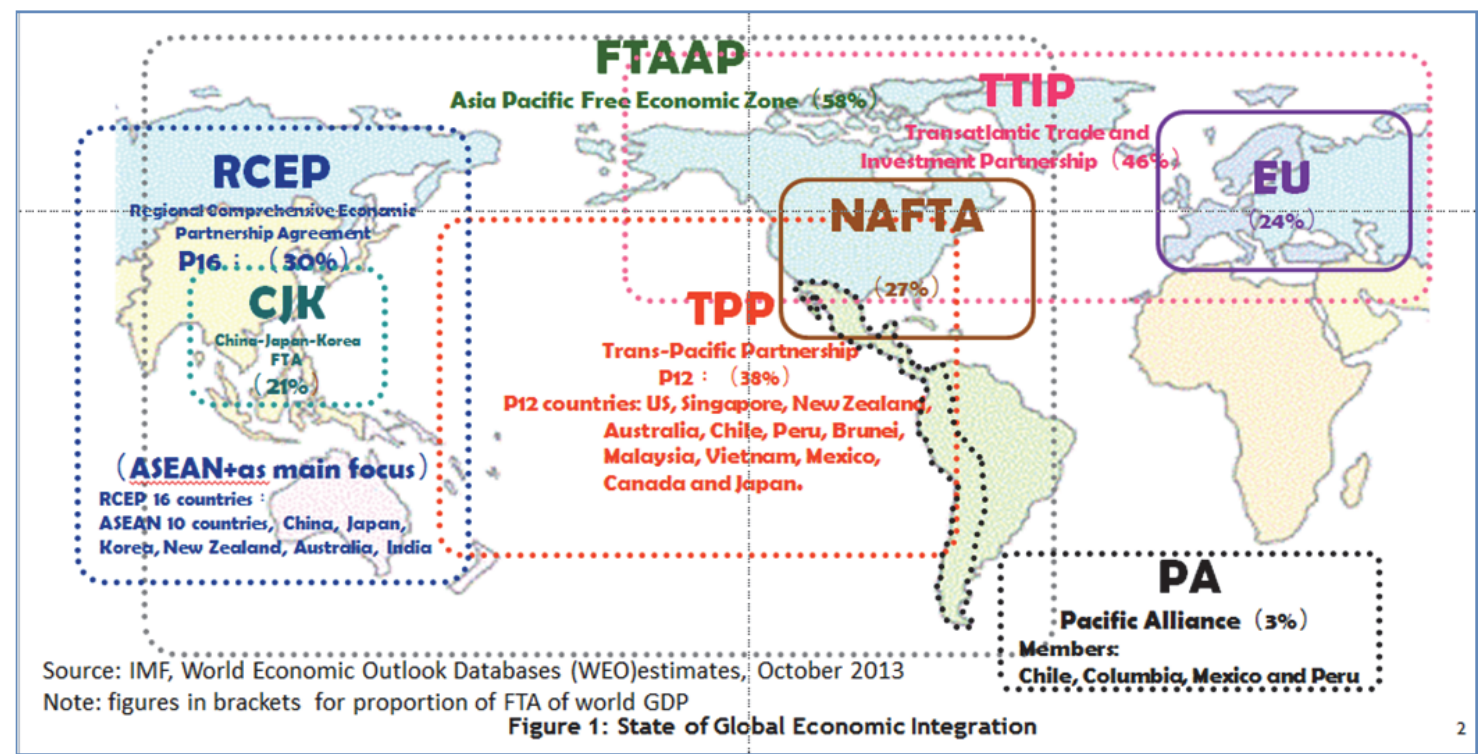

Source: IMF: World Economic Outlook Databases (October 2013) 
FIGURE 2

INTRAREGIONAL TRADE AS A PERCENTAGE OF TOTAL TRADE

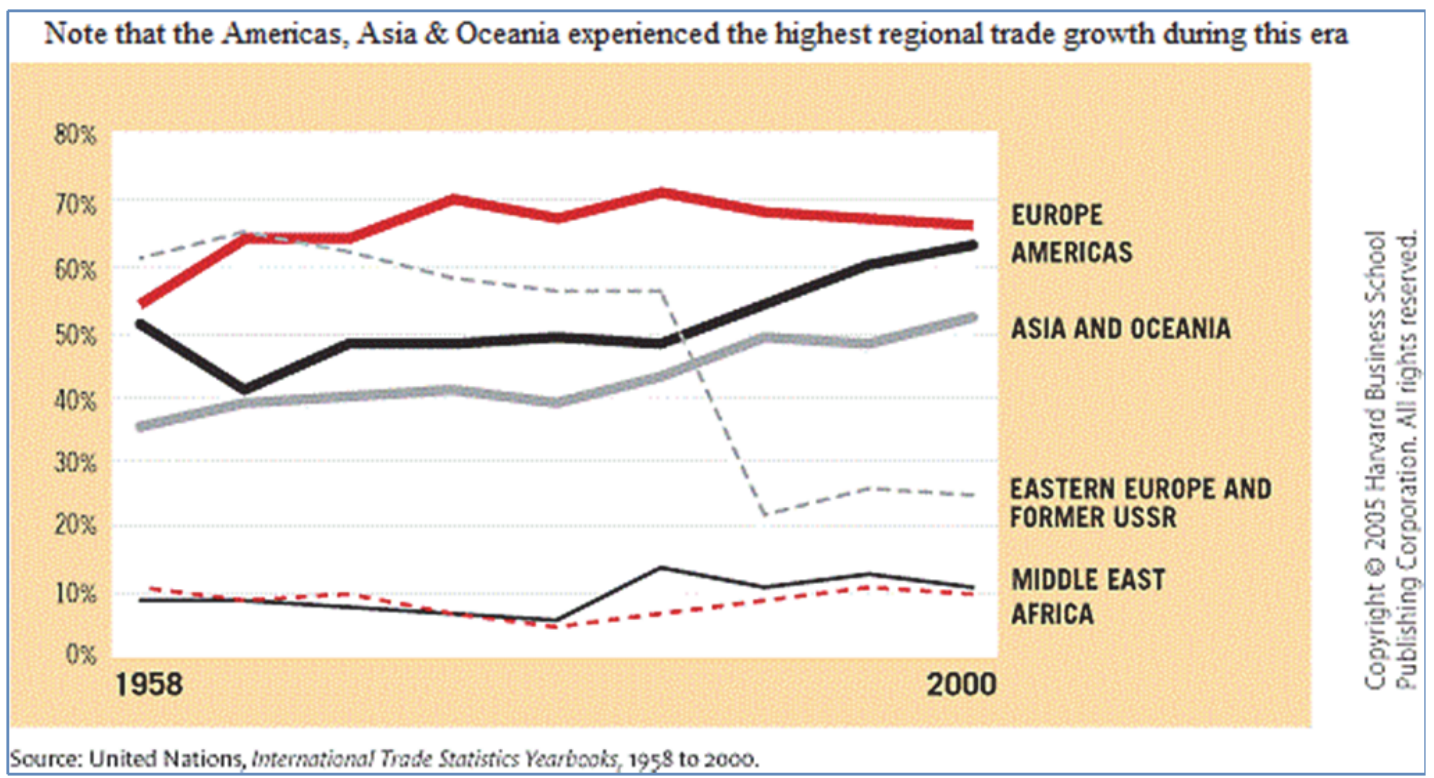

Source: Harvard Business School Publishing (2005)

FIGURE 3

LATIN AMERICA'S REGIONAL TRADE GROWTH DURING THE LAST TWO DECADES OF THE 2OTH CENTURY

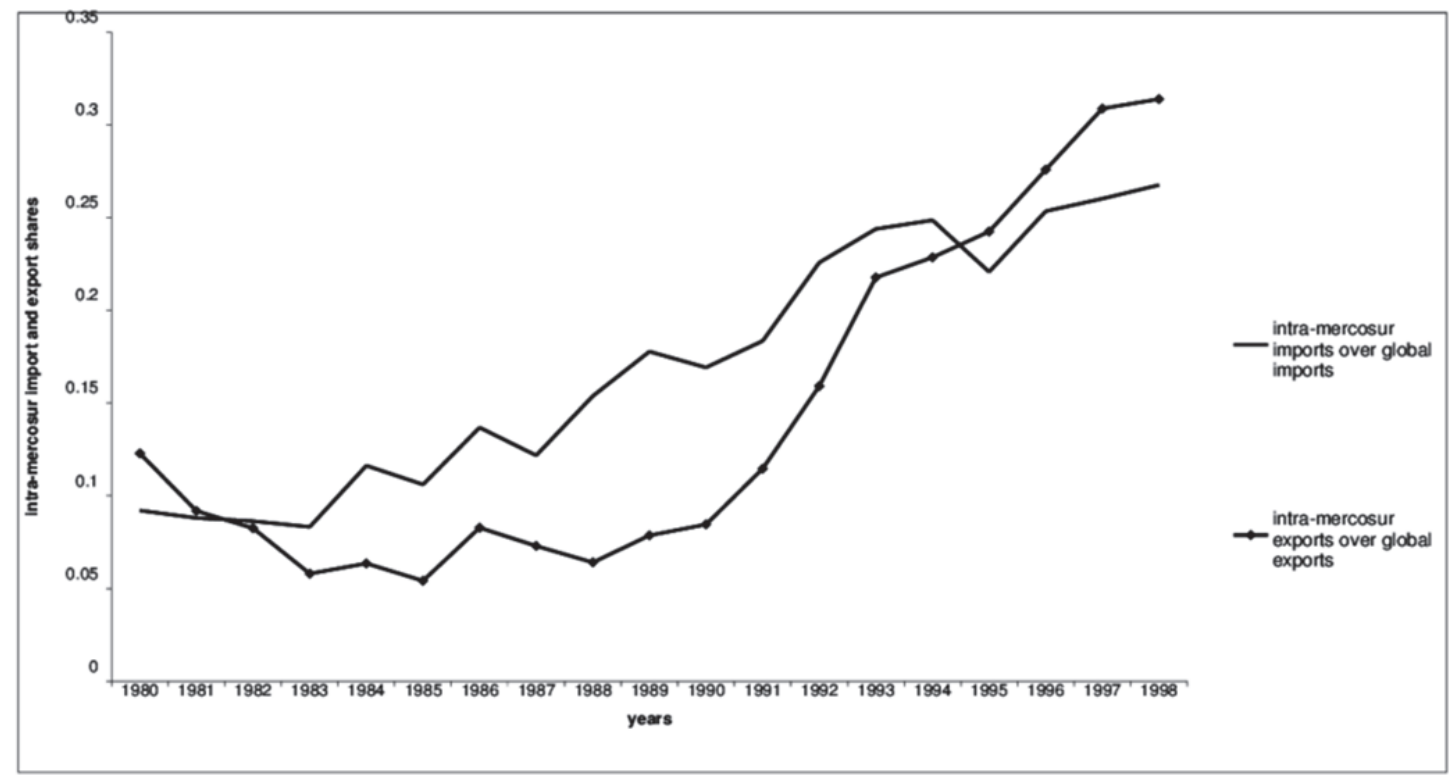

Source: IMF: World Economic Outlook Databases (October 2001) 